\title{
Neurologic signs and symptoms in a cohort of homosexual men followed for 4.5 years
}

\author{
K. Marder, MD, MPH; X. Liu, PhD; Y. Stern, PhD; G. Dooneief, MD, MPH; K. Bell, MD; \\ P. Schofield, MBBS, FRACP; N. Sacktor, MD; G. Todak, CSW; R. Friedman, RN; \\ A. Ehrhardt, PhD; Z. Stein, MD; J. Gorman, MD; and R. Mayeux, MD, MSE
}

\begin{abstract}
Article abstract--We traced the development of neurologic impairment in 207 homosexual men (123 human immunodeficiency virus [HIV]-positive and $84 \mathrm{HIV}$-negative controls) over 4.5 years of follow-up. We applied generalized estimating equations to logistic regression analyses with repeated measures to examine the differences between HIV-positive and HIV-negative subjects with respect to the likelihood of developing six neurologic outcomes derived from a factor analysis, significant neurologic impairment (modified Kurtzke disability score of $\geq 3$ ), or significant neuropsychological impairment. We found that, over time, HIV-positive subjects were more likely to develop clinically significant extrapyramidal signs and frontal release signs than HIV-negative subjects. Controlling for age or education, as CD4 count declined, the odds of developing significant extrapyramidal signs, abnormalities in alternating movements, frontal release signs, and a Kurtzke score $\geq 3$ increased. HIV-positive subjects were almost five times as likely (odds ratio [OR], 4.6; 95\% CI, 1.6 to 13.4) as HIV-negative subjects to stay the same or worsen neurologically on the next visit, and those with CD4 $\leq 200$ were 4.8 times as likely (OR, 4.8; $95 \% \mathrm{CI}, 2.2$ to 10.7 ) to maintain or worsen neurologically relative to those with higher CD4 counts. We conclude that neurologic impairment becomes increasingly apparent over time in HIV-infected men, especially in those with low CD4 counts.
\end{abstract}

NEUROLOGY 1995;45:261-267

Severe human immunodeficiency virus (HIV) infection is characterized by a multitude of neurologic signs and symptoms including long tract and extrapyramidal signs, peripheral neuropathy, and dementia. In an earlier cross-sectional assessment of 207 homosexual men that included HIV-negative and HIV-positive asymptomatic, mildly symptomatic, and moderately symptomatic patients, we found no difference in the frequency of neurologic signs and no decline in neurologic status with increasing medical symptomatology. ${ }^{1}$ The goal of the current analysis is to trace the development of neurologic signs and symptoms in this same cohort over 4.5 years.

Methods. Subjects. Two hundred seven homosexual men were recruited in late 1987 and early 1988 to participate in a 5-year follow-up study of HIV-infected subjects ( $\mathrm{n}=$ 123) and HIV-negative controls $(n=84)$. The majority of subjects were recruited via word of mouth, although two announcements were placed in "gay" monthly newslet- ters and one in a newspaper. Inclusion and exclusion criteria and screening procedures have been described elsewhere. ${ }^{2}$ All subjects were volunteers and gave informed consent. There were 168 subjects who entered the longitudinal phase of the study (113 HIV-positive and $55 \mathrm{HIV}$ negative) and were examined every 6 months for up to 4.5 years.

Assessments. At each visit, subjects received a standardized medical examination for the purpose of staging, and neurologic, neuropsychological, psychiatric, and psychosexual assessments. Laboratory tests at each assessment included complete blood count and lymphocyte typing. These assessments have been described previously, ${ }^{1,2}$ but relevant assessments will be summarized below. Subjects received $\$ 10.00$ per hour for their participation in the study. This was used to defray transportation costs and maintain participation.

Medical assessment. Physicians performed physical examinations targeted at HIV-related symptoms and signs. Subjects who met 1987 Centers for Disease Control criteria for acquired immunodeficiency syndrome $(\operatorname{AIDS})^{3}$ at baseline were not included in the study with

From the Departments of Neurology (Drs. Marder, Stern, Dooneief, Bell, Schofield, Sacktor, and Mayeux, and G. Todak) and Psychiatry (Drs. Stern, Ehrhardt, Stein, Gorman, and Mayeux, and G. Todak and R. Friedman), College of Physicians and Surgeons; the Gertrude H. Sergievsky Center (Drs. Marder, Liu, Stern, Dooneief, Bell, Schofield, Sacktor, Stein, and Mayeux); the HIV Center for Clinical and Behavioral Studies (Drs. Marder, Liu, Stern, Dooneief, Bell, Schofield, Sacktor, Ehrhardt, Stein, Gorman, and Mayeux, and G. Todak and R. Friedman); and the Division of Epidemiology (Drs. Stein and Mayeux), School of Public Health at Columbia University, New York, NY.

Supported by center grant P50-MH43520 from the National Institute of Mental Health/National Institute on Drug Abuse to the HIV Center for Clinical and Behavioral Studies, grant T32-MH19139 from the National Institute of Mental Health, and grants 3-M01-RR00645 and AG10963 from the National Institutes of Health.

Received March 10, 1994. Accepted in final form July 28, 1994.

Address correspondence and reprint requests to Dr. Karen Marder, Gertrude H. Sergievsky Center, 630 W. 168th Street, Box 16, New York, NY 10032. 
two exceptions. Because of the difficulty in clinically distinguishing between oral and esophageal candidiasis on routine physical examination, we did not exclude men with esophageal candidiasis, which is on its own a criterion for AIDS. We also did not use the presence of cognitive impairment as an exclusion criterion, because the purpose of the study was to assess nervous system abnormalities in relatively medically asymptomatic individuals.

Neurologic assessment. All neurologic examinations were performed by neurologists who were blind to the HIV status of the subjects. In the interests of maintaining blinding, the neurologic examinations were performed prior to the elicitation of symptoms. Each neurologic sign was coded separately so that individual signs could be examined and factor scores could be created based on individual items. A standard neurologic examination was performed. Items from the motor portion of the Unified Parkinson's Disease Rating Scale ${ }^{4}$ were included to assess extrapyramidal function. Neurologic symptoms were rated using the structured interview created by Richard Price, MD. ${ }^{5}$

Reliability of the neurologic examination was assessed by having three neurologists simultaneously rate signs and symptoms in 20 subjects. The neurologists took turns in performing the examination while the other two neurologists watched the examination and rated the individual items.

The neurologic data were summarized in two ways. First, an overall measure of neurologic disability was calculated for each subject, based on the Kurtzke Disability Status Scale for Multiple Sclerosis (Kurtzke score) ${ }^{6}$ The Kurtzke scale reflects both the number of areas of neurologic dysfunction (eg, pyramidal tract, cerebellum, brainstem) and the severity of impairment. Derivation of the Kurtzke score has been previously described. ${ }^{1}$ We chose a Kurtzke score of 3 or greater as indicative of a level of impairment that most neurologists would reliably detect and consider clinically meaningful. A subject with a Kurtzke score of 3 would have moderate neurologic disability but be fully ambulatory.

The second way in which the neurologic data were summarized was by performing a factor analysis on selected items of the neurologic examination. Creation of the neurologic factors has been previously described. ${ }^{7}$ First, 76 individual items were reduced to nine summary variables. Each summary variable consisted of the sum of the individual items comprising it. These individual items were coded as 0 (sign absent) or 1 (sign present). For example, the extrapyramidal factor was composed of 13 individual items, each coded as 0 or 1 . Therefore, a score of 2 might indicate the presence of rigidity in two limbs but would not indicate severity. These summary variables were included in a principal components factor analysis with subsequent varimax rotation. Six factors were produced which proved stable over the 10 visits and represented major neurologic domains. Based on what the authors believed indicated clinical significance, the factors were dichotomized into high and low. For example, a score of 2 or greater on the extrapyramidal factor was considered "high" and anything less than two was considered "low." Each individual's score for extrapyramidal status could then be classified as high or low. The six factors and the scores used to dichotomize them are shown in table 1 . The creation of neurologic factors facilitated the exploration of the relationship between the neurologic signs and symptoms and other relevant covariates.
Table 1. Six neurologic factors and their components

\begin{tabular}{|c|c|c|c|}
\hline Factor & Cutpoint & $\begin{array}{l}\text { No. items } \\
\text { included }\end{array}$ & Items \\
\hline Symptoms & $\geq 3$ & 11 & $\begin{array}{l}\text { All cognitive, motor, and } \\
\text { behavioral items on Price } \\
\text { questionnaire }\end{array}$ \\
\hline $\begin{array}{l}\text { Alternating } \\
\text { movements }\end{array}$ & $\geq 1$ & 8 & $\begin{array}{l}\text { Finger-tapping, opening } \\
\text { and closing hands, } \\
\text { pronation, supination, } \\
\text { foot-tapping }\end{array}$ \\
\hline $\begin{array}{l}\text { Frontal } \\
\quad \text { release } \\
\text { signs }\end{array}$ & $\geq 3$ & 7 & $\begin{array}{l}\text { Glabellar, snout, suck, and } \\
\text { palmomental reflexes; } \\
\text { grasp }\end{array}$ \\
\hline $\begin{array}{l}\text { Cranial } \\
\text { nerve signs }\end{array}$ & $\geq 2$ & 21 & All cranial nerve signs \\
\hline $\begin{array}{l}\text { Extra- } \\
\text { pyramidal } \\
\text { signs }\end{array}$ & $\geq 2$ & 13 & $\begin{array}{l}\text { Rigidity in all limbs, } \\
\text { bradykinesia, salivation, } \\
\text { gait, hypomimia, speech, } \\
\text { tremor (rest and action), } \\
\text { posture }\end{array}$ \\
\hline $\begin{array}{l}\text { Sensory } \\
\text { abnormalities }\end{array}$ & $\geq 5$ & 16 & $\begin{array}{l}\text { Pain and temperature, } \\
\text { vibration, position }\end{array}$ \\
\hline \multicolumn{4}{|c|}{$\begin{array}{l}\text { Each item is graded as } 0 \text { or } 1 \text {, and maximum score equals number o } \\
\text { items included. }\end{array}$} \\
\hline
\end{tabular}

Neuropsychological assessment. The neuropsychological battery, also administered blind to HIV status, assessed a number of areas including memory, language, executive or "frontal lobe" function, attention, visuospatial function, and motor speed. The tests are described elsewhere. ${ }^{1}$ The neuropsychological examiners did not interview subjects about their symptoms or signs and were not aware of the medical or neurologic findings; therefore, blinding could be maintained. In this analysis, performance on each test was compared with norms derived from populations of the same age and education. A global performance rating (GPR) was derived to summarize the neuropsychological performance at each visit. Performance was rated on a scale of 0 to 4 , based on age- and education-appropriate norms as ( 0 ) normal, (1) borderline (at least $1 \mathrm{SD}$ below the mean in two or more areas), (2) defective (at least $2 \mathrm{SD}$ below the mean in one area), (3) defective (at least $2 \mathrm{SD}$ below the mean in two or more areas), (4) defective (at least 2 SD below the mean in memory and two or more areas).

Statistical analysis. Analyses of the longitudinal data were performed by applying generalized estimating equations (GEE) to logistic regression analyses with repeated measures. ${ }^{8}$ The logistic analyses provide estimates of the odds of the occurrence of an outcome dependent on the values of the covariates. The outcomes included the six neurologic factors, the modified Kurtzke score, and the GPR. All outcomes were dichotomized based on the presence or absence of clinically significant findings. For example, the extrapyramidal factor was dichotomized based on the presence of two mild-to-moderate extrapyramidal signs (table 1 ).

Using GEE, we examined the differences between HIV-positive and HIV-negative subjects with respect to the likelihood of developing clinically significant findings for each outcome. Furthermore, with GEE, a statistically significant relationship between length of follow-up and an outcome indicates a change (increase or decrease) in the odds of an outcome occurring over time. We also included the interaction of time and HIV status as a co- 
Table 2. Baseline demographics

\begin{tabular}{|c|c|c|c|c|c|}
\hline & $\begin{array}{l}\text { HIV + (total }) \\
\quad(\mathbf{n}=\mathbf{1 1 3})\end{array}$ & $\begin{array}{c}\text { HIV - (total) } \\
(\mathbf{n}=\mathbf{5 5})\end{array}$ & $\begin{array}{l}\text { HIV+ (deaths) } \\
\quad(\mathrm{n}=33)\end{array}$ & $\begin{array}{l}\text { HIV+ }+(\mathbf{L T F U}) \\
\quad(\mathbf{n}=\mathbf{2 6})\end{array}$ & $\begin{array}{l}\text { HIV - (LTFU) } \\
\quad(\mathbf{n}=\mathbf{1 6})\end{array}$ \\
\hline Age & $38.4(8.2)$ & $38.6(8.6)$ & $40.4(8.4)$ & $36.1(7.1)$ & $39.0(9.2)$ \\
\hline Education & $16.0(2.5)$ & $16.7(2.3)$ & $16.1(2.7)$ & $15.7(2.1)$ & $16.9(2.1)$ \\
\hline CD4 count & $406.9(220.1)$ & $823.2(272.5)$ & $283.6(192.7)$ & $476.7(210.3)$ & $808.8(312.0)$ \\
\hline Kurtzke score & $1.2(0.6)$ & $1.1(0.6)$ & $1.3(0.6)$ & $1.1(0.7)$ & $0.9(0.6)$ \\
\hline GPR & $1.2(1.1)$ & $1.0(1.2)$ & $1.3(1.1)$ & $1.2(1.3)$ & $0.8(1.0)$ \\
\hline \multicolumn{6}{|c|}{ Numbers in parentheses are SE values. } \\
\hline \multicolumn{6}{|c|}{$\begin{array}{ll}\text { LTFU Lost to follow-up. } \\
\text { GPR Global performance rating. }\end{array}$} \\
\hline
\end{tabular}

variate in some analyses. A significant interaction of HIV status and follow-up time would indicate that the odds of an outcome occurring over time differs as a function of HIV status.

This statistical method takes into account the multiple visits per subject and the fact that the characteristics of a single individual over time are likely to be correlated with one another. The repeated measures for each subject (up to 10 per variable) are treated as a cluster. A second advantage of GEE is that it takes into account the status or changing value of each covariate and outcome at each visit.

A separate analysis was restricted to the HIV-positive subjects. The same outcome variables were examined with CD4, time, age, education, and GPR as covariates.

A second type of analysis employed was a Markov regression model. ${ }^{9}$ In this analysis, current status of outcome and risk factors were used to predict the probability of transition to specified outcomes on the next visit.

Results. Demographics. One hundred sixty-eight subjects (113 HIV-positive and $55 \mathrm{HIV}$-negative) were included in the longitudinal follow-up. The baseline characteristics of the HIV-positive and HIV-negative subjects are presented in table 2 . One of the HIV-negative subjects died and 16 were lost to follow-up (did not complete 10 visits). Among HIV-positive subjects, there were 33 deaths over 5 years, and 26 were lost to follow-up. Three of the HIV-positive subjects died after completing their 10th visit. Baseline CD4 counts of subjects who died differed significantly from those of HIVnegative subjects and from the other HIV-positive subjects (table 2). Other baseline characteristics did not differ between those who did and did not die. By visit 10 , there were 57 HIV-positive subjects and $39 \mathrm{HIV}$-negative subjects.

Prevalence of neurologic abnormalities. The prevalence of neurologic abnormalities at baseline in the 168 subjects is seen in table 3 . HIV-positive subjects had more symptoms than HIV-negative subjects at baseline $(p=0.05)$. The prevalence of the other neurologic factors and the Kurtzke score was not significantly different in HIV-positive compared with HIV-negative subjects, but neither age nor education were controlled for in the analysis. To assess whether those who developed neurologic impairment (factor scores above cutpoints) during
Table 3. Prevalence of neurologic outcomes at baseline

\begin{tabular}{|lcc|}
\hline & $\begin{array}{c}\text { \% HIV }- \\
(\mathbf{n}=\mathbf{5 5})\end{array}$ & $\begin{array}{c}\text { \% HIV+ } \\
(\mathbf{n}=\mathbf{1 1 3})\end{array}$ \\
Extrapyramidal signs $\geq 2$ & $7.3(4)$ & $2.7(3)$ \\
Frontal release signs $\geq 3$ & $3.6(2)$ & $4.4(5)$ \\
Alternating movements $\geq 1$ & $1.8(1)$ & $7.1(8)$ \\
Cranial nerve signs $\geq 2$ & $12.7(7)$ & $8.0(9)$ \\
Sensory abnormalities $\geq 5$ & $7.3(4)$ & $7.1(8)$ \\
Symptoms $\geq 3$ & $14.6(8)$ & $29.2(33)^{*}$ \\
Kurtzke score $\geq 3$ & $1.8(1)$ & $2.7(3)$ \\
Numbers in parentheses represent & number of subjects with each \\
particular outcome. & & \\
$* p=0.05$. &
\end{tabular}

the course of follow-up were the most ill, the HIVpositive subjects were classified into four groups (asymptomatic, mild symptoms not consistent with AIDS-related complex [ARC], ARC, and AIDS) at the visit when they first developed a score above the cutpoint on an individual neurologic factor. They were also classified by CD4 count at the first visit they demonstrated a neurologic factor score above cutpoint. As can be seen in table 4, neurologic endpoints were reached in subjects in all stages of illness. Among those with a Kurtzke score $\geq 3$, most had a low CD4 count. In contrast, the extrapyramidal sign and frontal release sign outcomes were reached by patients with variable levels of immunosuppression. Because factor scores were dichotomized into high and low, it is unlikely that a few subjects with abrupt large changes accounted for the neurologic changes. More likely, many or most people experience slight and gradual change over time.

Reliability of neurologic examination. Standardized neurologic examinations were performed in 20 subjects by three independent examiners blind to HIV status. Reliability was in the good-to-excellent range $^{10}$ for examination of mentation and cranial nerve function and in the fair-to-good range for pyramidal tract signs, cerebellar signs, sensory abnormalities, and extrapyramidal signs. Overall agreement (intraclass correlation) on the summary 
Table 4. Severity of HIV infection at visit when neurologic outcome is first demonstrated

\begin{tabular}{|c|c|c|c|c|c|}
\hline & $\begin{array}{l}\text { \% Asymp- } \\
\text { tomatic }\end{array}$ & $\%$ Mild & $\%$ ARC & $\%$ AIDS & $\begin{array}{c}\text { No. } \\
\text { subjects } \\
\text { developing } \\
\text { outeome }\end{array}$ \\
\hline $\begin{array}{l}\text { Extra- } \\
\text { pyramidal } \\
\text { signs } \geq 2\end{array}$ & $7.7(3)$ & $17.9(7)$ & $59.0(23)$ & $15.4(6)$ & 39 \\
\hline $\begin{array}{l}\text { Frontal } \\
\text { release } \\
\text { signs } \geq 3\end{array}$ & $22.2(4)$ & $22.2\{4\}$ & $38.9(7)$ & $16.7(3)$ & 18 \\
\hline \multirow[t]{2}{*}{$\begin{array}{l}\text { Kurtzke } \\
\text { score } \geq 3\end{array}$} & $0(0)$ & $22.7(5)$ & $45.5(10)$ & $31.8(7)$ & 22 \\
\hline & $\begin{array}{l}\text { \% with } \\
\text { CD4 } \geq 500\end{array}$ & \multicolumn{2}{|c|}{$\begin{array}{c}\text { \% with } \\
\text { CD4 } \\
\text { 200-500 }\end{array}$} & $\begin{array}{l}\text { \% with } \\
\text { CD4 } \leq 200\end{array}$ & $\begin{array}{c}\text { No. subjects } \\
\text { developing } \\
\text { outcome }\end{array}$ \\
\hline $\begin{array}{l}\text { Extra- } \\
\text { pyramidal } \\
\text { signs } \geq 2\end{array}$ & $10.3(4)$ & \multicolumn{2}{|c|}{$59.0(23)$} & $30.8(12)$ & 39 \\
\hline $\begin{array}{l}\text { Frontal } \\
\text { release } \\
\text { signs } \geq 3\end{array}$ & $0(0)$ & \multicolumn{2}{|c|}{$66.7(12)$} & $33.3(6)$ & 18 \\
\hline $\begin{array}{l}\text { Kurtzke } \\
\text { score } \geq 3\end{array}$ & $9.1(2)$ & \multicolumn{2}{|c|}{$22.7(5)$} & $68.2(15)$ & 22 \\
\hline \multicolumn{6}{|c|}{$\begin{array}{l}\text { Numbers in parentheses represent number of subjects with each particular out- } \\
\text { come. }\end{array}$} \\
\hline
\end{tabular}

neurologic measure, the modified Kurtzke score, was 0.89 .

Progression of neurologic factors and summary variables over time. HIV-positive versus HIV-negative subjects. To determine whether the six neurologic factors (table 1) changed over time and whether the presence of HIV infection correlated with the severity of neurologic signs and symptoms, we examined the cohort (HIV-positive and HIV-negative) over all visits. The six neurologic factors (table 1), the neurologic summary score (Kurtzke score), and the neuropsychological summary variable (GPR) were dichotomized into high and low severity and were considered as outcome variables. HIV status, time from first visit for the HIV-negative and HIV-positive subjects separately, and the interaction of time by HIV status were included as covariates. By GEE (table 5, column 1), at every visit HIV-positive subjects were more likely to have more symptoms (cognitive, motor, and mood complaints) and have a higher Kurtzke score $(\geq 3)$ than HIV-negative subjects. The odds per year of having clinically meaningful symptoms and frontal release signs significantly decreased over time in the HIV-negative group. The odds of developing extrapyramidal signs increased over time for the HIV-positive subjects. The odds of developing global neuropsychological impairment (GPR $\geq 3$ ) decreased in both HIV-negative and HIV-positive subjects over time. In contrast, with successive visits, impairment in alternating movements, sensory impairment, and a Kurtzke score $\geq 3$ were more likely to be present in both groups. There was a significant time-by-HIV interaction for the symptoms, extrapyramidal signs, and the frontal factors. This
Table 5. Odds ratios for the development of neurologic outcomes: HIV+ and HIV-subjects

\begin{tabular}{|c|c|c|c|c|}
\hline $\begin{array}{l}\text { Outcome } \\
\text { variables }\end{array}$ & $\begin{array}{l}\text { HIV status* } \\
\text { (HIV+/HIV-) }\end{array}$ & Time (HIV-) & Time (HIV+) & HIV by time \\
\hline $\begin{array}{l}\text { Extra- } \\
\text { pyramidal } \\
\text { signs }\end{array}$ & $0.4(0.2-1.1)$ & $1.3(1.0-1.6)$ & $2.0(1.6-2.4) \div$ & $1.6(1.1-2.1) \ddagger$ \\
\hline $\begin{array}{l}\text { Frontal } \\
\text { release } \\
\text { signs }\end{array}$ & $0.8(0.2-2.7)$ & $0.3(0.1-0.6)_{\ddagger}^{\ddagger}$ & $0.8(0.2-2.4)$ & $2.7(1.1-6.5)+$ \\
\hline $\begin{array}{l}\text { Alternating } \\
\text { movements }\end{array}$ & $1.1(0.6-1.9)$ & $1.2(1.0-1.4) \neq$ & $1.2(1.0-1.4) \ddagger$ & \\
\hline $\begin{array}{l}\text { Cranial } \\
\text { nerve signs }\end{array}$ & $0.6(0.4-1.1)$ & $1.0(0.8-1.1)$ & $1.0(0.8-1.1)$ & \\
\hline $\begin{array}{l}\text { Sensory } \\
\text { abnor- } \\
\text { malities }\end{array}$ & $1.2(0.7-2.0)$ & $1.1(1.0-1.3) \ddagger$ & $1.1(1.0-1.3) \ddagger$ & \\
\hline Symptoms & $2.1(1.0-4.1) \div$ & $0.8(0.6-1.0) \neq$ & $1.0(0.9-1.1)$ & $1.3(1.0-1.6) \frac{4}{4}$ \\
\hline $\begin{array}{l}\text { Kurtzke } \\
\text { score } \geq 3\end{array}$ & $5.3(1.6-17.5) \ddagger$ & $1.4(1.1-1.7) \ddagger$ & $1.4(1.1-1.7)+$ & \\
\hline GPR $\geq 3$ & $1.0(0.4-2.4)$ & $0.6(0.6-0.7) \ddagger$ & $0.6(0.6-0.7) \ddagger$ & \\
\hline \multicolumn{5}{|c|}{ Odds ratios are per year. } \\
\hline \multicolumn{5}{|c|}{ Numbers in parentheses are $95 \%$ confidence intervals. } \\
\hline \multicolumn{5}{|c|}{ 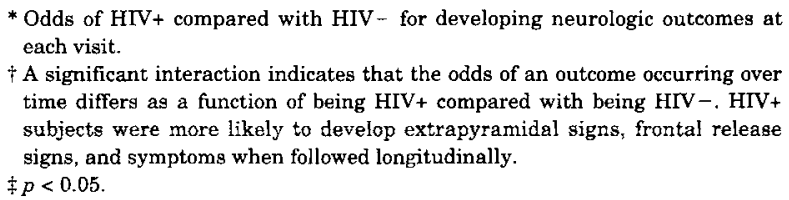 } \\
\hline
\end{tabular}

Table 6. Odds ratios for the development of neurologic outcomes: HIV+ subjects only

\begin{tabular}{|lccc|}
\hline $\begin{array}{l}\text { Outcome } \\
\text { variables }\end{array}$ & Time & $\begin{array}{c}\text { Baseline } \\
\text { age (yr) }\end{array}$ & $\begin{array}{c}\text { Education } \\
\text { (yr) }\end{array}$ \\
$\begin{array}{l}\text { Extrapyramidal } \\
\text { signs }\end{array}$ & $2.0(1.7-2.4)^{*}$ & $1.1(1.0-1.1)^{*}$ & $1.0(0.9-1.1)$ \\
$\begin{array}{l}\text { Frontal release } \\
\text { signs }\end{array}$ & $0.8(0.5-1.1)$ & $1.0(1.0-1.1)$ & $0.9(0.8-1.0)^{*}$ \\
$\begin{array}{l}\text { Alternating } \\
\text { movements }\end{array}$ & $1.2(0.9-1.4)$ & $1.1(1.0-1.1)^{*}$ & $0.9(0.8-1.1)$ \\
$\begin{array}{l}\text { Cranial nerve } \\
\text { signs }\end{array}$ & $1.0(0.8-1.2)$ & $1.0(1.0-1.1)^{*}$ & $1.0(0.9-1.2)$ \\
$\begin{array}{l}\text { Sensory } \\
\text { abnormalities }\end{array}$ & $1.2(1.0-1.3)^{*}$ & $1.0(1.0-1.1)$ & $0.8(0.8-0.9)^{*}$ \\
$\begin{array}{l}\text { Symptoms } \\
\text { Kurtzke score } \geq 3\end{array}$ & $1.0(0.9-1.1)$ & $1.0(1.0-1.0)$ & $1.0(0.9-1.1)$ \\
GPR $\geq 3$ & $0.7(0.6-0.8)^{*}$ & $1.0(1.0-1.1)$ & $1.0(0.9-1.2)$ \\
Numbers in parentheses are 95\% confidence intervals. & \\
$* p<0.05$. & & & \\
& & &
\end{tabular}

suggests that when followed longitudinally, the HIV-positive subjects were more likely to develop clinically significant extrapyramidal signs, frontal release signs, and cognitive, motor, and $\operatorname{mood}$ symptoms than the HIV-negative subjects.

HIV-positive only. GEE analysis was then restricted to the HIV-positive subjects (table 6). First, the effects of follow-up time, age at baseline, and education on the outcome variables (six neurologic factors, Kurtzke score, and GPR) were examined. The odds of developing a clinically significant level of extrapyramidal signs, sensory abnormalities, or 
Table 7. Odds ratios for the development of neurologic outcomes: HIV+ subjects only

\begin{tabular}{|c|c|c|c|c|}
\hline $\begin{array}{l}\text { Outcome } \\
\text { variables }\end{array}$ & CD4 $\leq 200$ & $200<\mathrm{CD} 4<500$ & GPR & Age \\
\hline $\begin{array}{l}\text { Extra- } \\
\text { pyramidal } \\
\text { signs }\end{array}$ & $3.3(1.1-10.0)^{*}$ & $3.4(1.3-8.9)^{*}$ & $1.4(0.7-3.1)$ & $1.1(1.0-1.1)^{*}$ \\
\hline $\begin{array}{l}\text { Alternating } \\
\text { movements }\end{array}$ & $4.3(1.9-9.7)^{*}$ & $2.9(1.3-6.3)^{*}$ & $4.9(2.2-11.2)^{*}$ & $1.1(1.0-1.1)^{*}$ \\
\hline $\begin{array}{l}\text { Cranial } \\
\text { nerve signs }\end{array}$ & $1.5(0.6-3.4)$ & $0.8(0.4-1.8)$ & $2.2(0.9-5.5)$ & $1.0(1.0-1.1)^{*}$ \\
\hline \multirow[t]{2}{*}{$\begin{array}{l}\text { Kurtzke } \\
\text { score }\end{array}$} & $19.2(2.6-141.3)^{*}$ & $4.8(0.6-36.2)$ & $2.2(0.7-6.7)$ & $1.1(1.0-1.2)^{*}$ \\
\hline & & & & Education \\
\hline $\begin{array}{l}\text { Frontal } \\
\text { release } \\
\text { signs }\end{array}$ & $43.8(7.6-252.9)^{*}$ & $48.1(14.3-162.0)^{*}$ & $2.7(0.7-9.7)$ & $0.9(0.8-1.0)$ \\
\hline $\begin{array}{l}\text { Sensory } \\
\text { abnor- } \\
\text { malities }\end{array}$ & $1.5(0.8-2.9)$ & $0.8(0.4-1.5)$ & $1.2(0.6-2.6)$ & $0.9(0.8-0.9)^{*}$ \\
\hline \multirow[t]{2}{*}{ Symptoms } & $1.0(0.6-1.5)$ & $0.8(0.5-1.1)$ & $1.5(1.0-2.5)$ & \\
\hline & & & Kurtzke & Time \\
\hline GPR & $0.9(0.4-1.9)$ & $0.7(0.4-1.2)$ & $2.7(1.1-6.6)^{*}$ & $0.6(0.5-0.8)^{*}$ \\
\hline \multicolumn{5}{|c|}{ Numbers in parentheses are $95 \%$ confidence intervals. } \\
\hline
\end{tabular}

Kurtzke score $\geq 3$ increased over time, while the odds of developing significant neuropsychological impairment (GPR $\geq 3$ ) decreased over time. Baseline age was associated with extrapyramidal signs, alternating movements, cranial nerve signs, and high level of neurologic disability (Kurtzke score $\geq 3$ ), indicating that older men tended to have more impairment on these outcomes than younger men. The odds of developing clinically significant frontal release signs or sensory abnormalities were increased in those subjects with lower education.

A model was then constructed with GPR, CD4, and age or education as covariates, and the six neurologic outcome variables were dichotomized as described above. Adjusting for the effects of age or education, the odds of developing alternating movement abnormalities, frontal release signs, sensory abnormalities, or a Kurtzke score $\geq 3$ increased with declining CD4 count. Impaired cognitive status (GPR $\geq 3$ ) increased the odds of having impairment in alternating movements.

CD4 was then categorized as $\leq 200$, between 200 and 500 , or $\geq 500$. CD $4 \geq 500$ was then considered as a reference group, instead of being treated as a continuous variable (table 7): When CD4 was stratified as $\leq 200$ or 200 through 500, the odds of developing clinically significant extrapyramidal signs, alternating movements, and frontal release signs and a Kurtzke score $\geq 3$ was higher for those with CD4 $\leq 200$ than for those with a CD4 $\geq 500$. The odds of developing significant extrapyramidal signs, alternating movements, and frontal release signs were also increased for those in the 200 to 500 range compared to those with CD4 $\geq 500$ (table 7).

Lastly, GPR $\geq 3$ was treated as an outcome (table
7). The relationship between $\mathrm{CD} 4$ count, stratified as above, Kurtzke score, and time and the development of clinically significant cognitive impairment was examined. Among the HIV-positive subjects there was no relationship between CD4 and GPR, when adjusted for Kurtzke score. The odds of developing cognitive impairment (GPR $\geq 3$ ) increased with greater neurologic disability, as measured by the Kurtzke. The odds of developing clinically significant cognitive impairment decreased over time.

Transitional probabilities. A Markov regression model was used to determine which factors were important in the transition or maintenance of a moderate level of neurologic impairment (defined as a score of 3 or greater on the Kurtzke disability status score). From the previous analysis, we know that the odds of having a Kurtzke score of 3 or greater increased with age, with HIV-positive status, and with lower $\mathrm{CD} 4$ counts.

We investigated the effect of these covariates on the transition probability of developing a Kurtzke score $\geq 3$. When the entire cohort was examined, age and HIV status were independent predictors of transition to Kurtzke $\geq 3$ on the next visit. Given age and Kurtzke score measured on a visit, the odds ratio of maintaining or developing a higher Kurtzke score $(\geq 3)$ on the next visit in the HIV-positive group relative to the HIV-negative group was 4.6 (95\% CI, 1.6 to 13.4). Given current age and Kurtzke score, the odds ratio for maintaining or developing a higher Kurtzke score on the next visit in HIV-positive patients with CD4 $<200$ relative to those with higher CD4 counts was 4.8 (95\% CI, 2.2 to 10.7 ).

From this set of analyses, we can conclude that over time, HIV-positive subjects are more likely to develop clinically significant extrapyramidal signs and frontal release signs than HIV-negative subjects. Controlling for the effects of age, since neurologic impairment may be more common in older subjects, the odds of developing significant extrapyramidal signs, abnormalities in alternating movements, and global neurologic disability (Kurtzke score $\geq 3$ ) increase as CD4 declines. Controlling for the effects of education, the likelihood of developing frontal release signs also increases as CD4 declines. The odds of having clinically significant abnormalities in alternating movements is increased in subjects with severe cognitive impairment (GPR $\geq 3$ ). Impairment in these neurologic domains is apparent in both those with CD4 counts $\leq 200$ and those with counts between 200 and 500 . In summary, those subjects with CD4 counts $\leq 200$ were more likely to develop significant neurologic disability. Subjects with greater neurologic disability had a higher probability of developing significant cognitive impairment. No relationship between low CD4 count and cognitive impairment was seen, after adjustment for neurologic impairment (Kurtzke score).

Discussion. We have shown that neurologic signs, particularly abnormalities of rapid alternating 
movements, frontal release signs, and extrapyramidal signs, are present in mildly to moderately immunologically compromised patients and that they are more likely to develop over time. This may reflect early involvement of subcortical structures as demonstrated by PET, ${ }^{11}$ SPECT, ${ }^{12}$ and MR spectroscopy. ${ }^{13}$ This is the first systematic longitudinal follow-up of neurologic impairment in HIV infection.

There are several unique aspects to this study. In contrast to the Multicenter AIDS Cohort Study, ${ }^{14}$ rather than performing a screening assessment for neurologic impairment and then examining only those meeting screening criteria, all subjects received detailed, reliable, standardized assessments at each visit. This allowed the detection of subtle neurologic impairment that although not functionally disabling, demonstrated nervous system involvement prior to the development of severe immunologic compromise.

The factor analysis allowed an exploration of impairment in specific stable neurologic domains in relation to immunologic and neuropsychological measures. It is extremely unlikely that the increasing neurologic impairment is accounted for by a few people with abrupt, large changes. Dichotomizing the items that comprised each of the neurologic factors into present or absent meant that, for example, a subject with severe rigidity in one limb received the same score as someone with mild rigidity. In addition, subjects with varying severity of HIV infection and not exclusively those with CD4 count below 200 developed the neurologic outcomes (tables 3 and 4). Even after controlling for age or education using GEE, the odds of developing extrapyramidal signs, alternating movement abnormalities, and frontal release signs were increased even in those subjects with CD4 counts in the 200 to 500 range, compared with those subjects with CD4 over 500 (table 7).

The findings here corroborate and extend earlier cross-sectional descriptions of neurologic impairment in subjects with AIDS. ${ }^{15-17}$ Frontal release signs and abnormalities in rapid alternating movements and extrapyramidal signs were common, although abnormalities in sensation were most common.

There are several limitations to this study. Although we have documented that neurologic impairment occurs at all stages of HIV infection, we could not determine whether those who are either immunologically or cognitively more impaired gradually worsen neurologically or whether there is a sudden decline in neurologic function when a certain immunologic status is attained. The analyses reported here do not adequately capture the rate of change of HIV-positive subjects relative to HIV-negative subjects. For example, the learning effect apparent in the improvement in GPR in both groups is less robust in the HIV-positive group suggesting that the effects of HIV may be mediating this relative lack of improvement. ${ }^{18}$
This study primarily describes mild-to-moderate neurologic impairment associated with HIV infection. The study was designed to describe the relationship between neurologic, neuropsychological, and medical findings early in the course of HIV infection. Few subjects reached the endpoints of severe neurologic impairment over the 4.5 years. The differences detected between HIV-positive and -negative men may be underestimated because HIV-positive subjects were often not examined when they became extremely ill. Only subjects who were ambulatory and able to come to the center were examined neurologically and neuropsychologically, although phone contact was maintained throughout the study. Of the 33 HIV-positive patients who died, the average time from their last visit until death was about 8 months. This suggests that important neurologic outcomes may not have been recorded. It also means that factors such as opportunistic infections may not have influenced neurologic and neuropsychological performance to the extent that they might have, had this been a hospital-based cohort. For example, among 14 subjects who developed Pneumocystis carinii pneumonia, only two developed a Kurtzke score of 3 or above. This may also explain why among the HIVpositive subjects global cognitive function appeared to improve over time. There may have been differential loss to follow-up of the most cognitively impaired individuals.

We have documented that, over time, HIV-positive subjects are more likely than HIV-negative subjects to develop neurologic disability and that there are specific neurologic signs (extrapyramidal and frontal release) that are more likely to develop in HIV-positive subjects over time compared with HIV-negative subjects, particularly those who are immunosuppressed. Detection of these early signs of impairment may be important in targeting those at risk for severe neurologic impairment.

\section{References}

1. Stern Y, Marder K, Bell K, et al. Multidisciplinary baseline assessment of homosexual men with and without human immunodeficiency virus infection. III. Neurologic and neuropsychologic findings. Arch Gen Psychiatry 1991;48:131. 138.

2. Gorman JM, Kertzner R, Todak G, et al. Multidisciplinary baseline assessment of homosexual men with and without human immunodeficiency virus infection. I. Overview of study design. Arch Gen Psychiatry 1991;48:120-123.

3. Centers for Disease Control. CDC classification system for human T-lymphotropic virus type III/lymphadenopathyassociated virus infections. MMWR Morb Mortal Wkly Rep 1986;35:334-339.

4. Fahn S, Marsden C, Calne D, eds. Recent developments in Parkinson's disease. Florham Park, NJ: Macmillan Healthcare Information, 1987;2:153-163.

5. Price RW, Brew B, Sidtis J, Rosenblum M, Sheck A, Cleary P. The brain in AIDS: central nervous system HIV-1 infection and AIDS dementia complex. Science 1988;239:586-592.

6. Kurtzke JF. Rating neurologic impairment in multiple sclerosis: an expanded disability status scale (EDSS). Neurology 1983;33:1444-1452.

7. Marder K, Stern Y, Malouf R, et al. Neurologic and neuro- 
psychological manifestations of human immunodeficiency virus infection in intravenous drug users without acquired immunodeficiency syndrome: relationship to head injury. Arch Neurol 1992;49:1169-1175.

8. Liang KY, Zeger SL. Longitudinal data analysis using generalized linear models. Biometrika 1986;73:13-22.

9. Zeger SL, Qaqish B. Markov regression models for time series: a quasi-likelihood approach. Biometrics 1988;44:10191031.

10. Fleiss JL. Statistical methods for rates and proportions. 2nd ed. New York: John Wiley \& Sons, 1981:218.

11. Rottenberg DA, Moeller JR, Strother SC, et al. The metabolic pathology of the AIDS dementia complex. Ann Neurol 1987;22:700-706.

12. Kramer E, Sanger J. Brain imaging in acquired immunodeficiency syndrome dementia complex. Semin Nucl Med 1990;20:353-363.

13. Deicken RF, Hubesch B, Jensen $P$, et al. Alterations in brain phosphate metabolite concentrations in patients with human immunodeficiency virus infection. Arch Neurol 1991;48:203-209.

14. McArthur JC, Cohen BA, Selnes OA, et al. Low prevalence of neurological and neuropsychological abnormalities in otherwise healthy HIV-1 infected individuals: results from the Multicenter AIDS Cohort Study. Ann Neurol 1989;26:601-611.

15. Navia BA, Jordan BD, Price RW. The AIDS dementia complex. I. Clinical features. Ann Neurol 1986;19:517-524.

16. Goethe KE, Mitchell JF, Marshall DW, et al. Neuropsychological and neurological function of human immunodeficiency virus seropositive individuals. Arch Neurol 1989; 46:129-133.

17. Maj M, Satz P, Janssen R, et al. WHO neuropsychiatric AIDS study, cross-sectional phase II. Arch Gen Psychiatry 1994;51:51-60.

18. Stern $Y$, Marder K, Tang M, et al. Association of cognitive and neurological decline with mortality in seropositive gay men. In: Neuroscience of HIV infection: basic and clinical frontiers. Amsterdam, 1992.

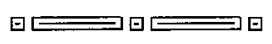

\title{
Cognitive performance after progression to AIDS: A longitudinal study from the Multicenter AIDS Cohort Study
}

\author{
O.A. Selnes, PhD; N. Galai, PhD; H. Bacellar, MA; E.N. Miller, PhD; J.T. Becker, PhD; \\ J. Wesch, PhD; W. Van Gorp, PhD; and J.C. McArthur, MBBS, MPH
}

\begin{abstract}
Article abstract-Objective: To describe changes in cognitive functioning before and after development of an acquired immune deficiency syndrome (AIDS)-defining illness or CD4+ lymphocyte count $<200 / \mathrm{mm}^{3}$ in participants in the Multicenter AIDS Cohort Study. Methods: The study population included participants who either were diagnosed with an AIDS-defining illness $(n=52)$ or had at least one measurement of CD4+ count $<200 / \mathrm{mm}^{3}(n=57)$ and who had at least four neuropsychological (NP) evaluations, two or more before and two or more after the AIDS diagnosis. A group of subjects with clinical diagnosis of dementia $(n=29)$ was also included for comparison. The NP test battery included measures of attention, memory, constructional abilities, and psychomotor speed. Longitudinal data analysis, using the generalized estimating equation, was performed separately for each NP measure. Time was measured in months from the date of clinical AIDS or CD4+ $<200 / \mathrm{mm}^{3}$. Results: Before AIDS, the dementia group showed significant decline (slope different from zero) only on measures of psychomotor speed. For all other measures, there was no evidence of decline in performance before AIDS for the other groups. After development of AIDS, the group with clinical AIDS showed significant decline on psychomotor speed but none on the other cognitive measures. The group with CD4+<200/ $\mathrm{mm}^{3}$ did not show significant decline on any of the cognitive measures after AIDS. As expected, the dementia group showed significant decline on all measures. Sensory neuropathy was associated with a significant decline in performance on measures of psychomotor speed after AIDS. Antiretroviral therapy was not associated with any measurable changes in NP performance. Conclusion: These results are consistent with previous findings showing no significant decline in cognitive functions before AIDS, unless overt dementia is present, and no decline in immunosuppressed subjects who have had no AIDS-defining illness. By contrast, in subjects who have developed clinical AIDS, there is mild decline in fine motor skills but no significant change in other cognitive domains.
\end{abstract}

NEUROLOGY 1995;45:267-275

Cognitive impairment is a well-recognized complication of human immunodeficiency virus (HIV) infection. In its most severe form, this cognitive im- pairment manifests itself as a dementia syndrome with symptoms severe enough to influence activities of daily living. The incidence of HIV-1 demen-

From Johns Hopkins University (Drs. Selnes and Galai, and H. Bacellar and J.C. McArthur), Baltimore, MD; the University of California at Los Angeles (Drs. Miller and Van Gorp), Los Angeles, CA; the University of Pittsburgh (Dr. Becker), Pittsburgh, PA; and Northwestern University School of Medicine (Dr. Wesch), Chicago, IL.

Supported by NIH grants AI-35042, AI-35403, AI-35039, AI-35040, AI-35041, and RR 00072

Received June 27, 1994. Accepted in final form July 26, 1994.

Address correspondence and reprint requests to Dr. Ola A. Selnes, Cognitive Neurology, Meyer 222, 600 North Wolfe Street, Baltimore, MD $21287-7222$. 